\title{
Demonstration and Feasibility Analyses of Using the Dual-Purpose Canister Drain Pipe to Support the Filling Process \\ Spent Fuel and Waste Disposition
}

\author{
Prepared for \\ US Department of Energy \\ Spent Fuel and Waste Science and \\ Technology \\ Elvis Dominguez-Ontiveros \\ Oak Ridge National Laboratory
}

March 31, 2019

M4SF-19OR0103050116

ORNL/SPR-2019/1130 



\section{DISCLAIMER}

This information was prepared as an account of work sponsored by an agency of the U.S. Government. Neither the U.S. Government nor any agency thereof, nor any of their employees, makes any warranty, expressed or implied, or assumes any legal liability or responsibility for the accuracy, completeness, or usefulness, of any information, apparatus, product, or process disclosed, or represents that its use would not infringe privately owned rights. References herein to any specific commercial product, process, or service by trade name, trade mark, manufacturer, or otherwise, does not necessarily constitute or imply its endorsement, recommendation, or favoring by the U.S. Government or any agency thereof. The views and opinions of authors expressed herein do not necessarily state or reflect those of the U.S. Government or any agency thereof. 



\section{SUMMARY}

This report documents experiments that are being used to determine the feasibility of filling dual-purpose canisters (DPCs) using the existing drain pipe. Mercury was identified as a surrogate filler for the initial experiments. Oak Ridge National Laboratory's Target Test Facility (TTF), which is a full-scale Spallation Neutron Source (SNS) prototypical mercury loop, is being used for the planned pipe experiments using mercury. The pipe experiments were divided into two phases to provide a separate effects approach to the problem and to allow for development of system scalability. The first phase included taking strain measurements in a short length pipe, as well as measurements of flow-induced vibration. The second phase consists of the design and construction of a separated mercury flow loop capable of hosting exchangeable test sections and more localized instrumentation. Data acquisition of Phase I was performed during this reporting time period, and subsequent data reduction and data analysis will be performed in the future. 
This page is intentionally left blank. 


\section{CONTENTS}

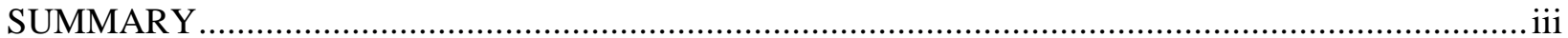

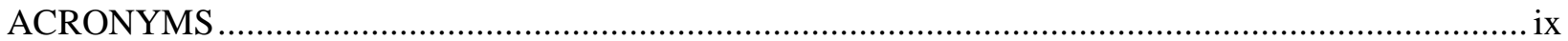

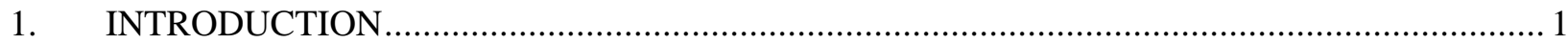

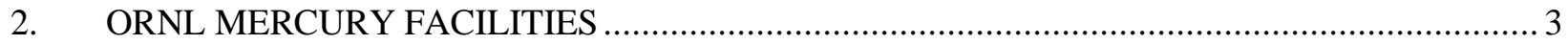

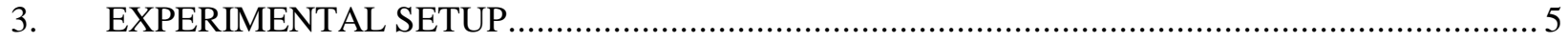

3.1 Experimental Program: Phase I............................................................................ 5

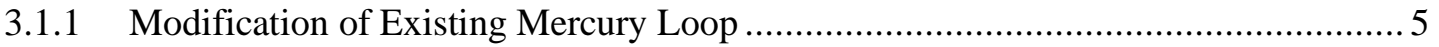

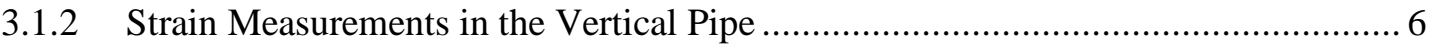

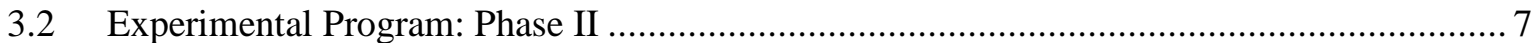

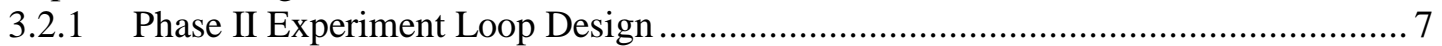

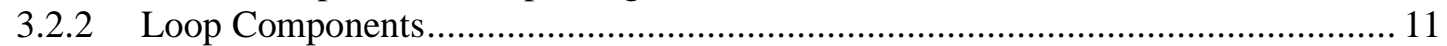

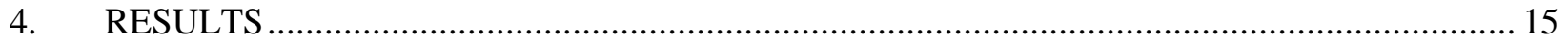

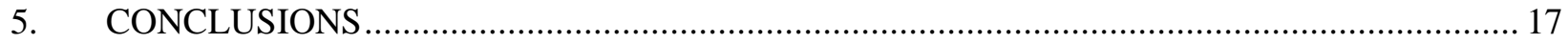

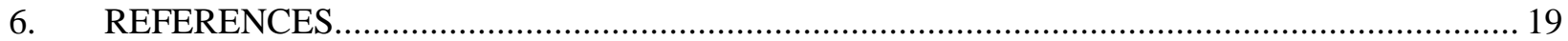


This page is intentionally left blank. 


\section{LIST OF FIGURES}

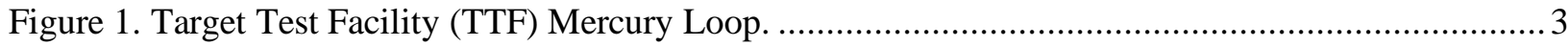

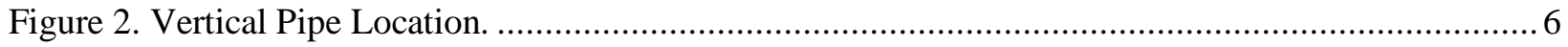

Figure 3. Vertical Pipe with Distributed Fiber Optic Sensor for Strain Measurements. .......................... 7

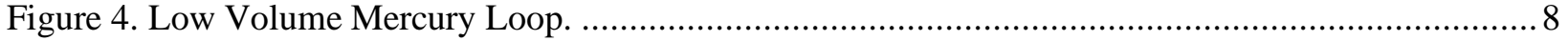

Figure 5. Pipe Entrance for Annular Type Inlet Flow. ….............................................................

Figure 6. Analytical Solutions of Expected Mercury Film Thickness for Pipe Diameters Between 12.7-25.4 mm under the Laminar Internal Annular Film Flow Assumption.

Figure 7. Pipe Strain at Bottom Wall of the Elbow. The Mercury Column Provides a Measurable Strain on the Outside Wall. 15

Figure 8. Frequency of Liquid Mercury Impingement at Bottom Surface of Vertical Pipe. 16 


\section{LIST OF TABLES}

Table 1. Typical canister drain-pipe sizes and experimental pipe tested in Phase I...............................5

Table 2. Expected film thickness for various flow rates with mercury and water. ................................ 11 


\section{ACRONYMS}

CFD computational fluid dynamics

DAQ data acquisition system

DOE US Department of Energy

DPC dual-purpose canister

FBGs fiber Bragg gratings

FY fiscal year

ORNL Oak Ridge National Laboratory

PTFE polytetrafluoroethylene

SNF spent nuclear fuel

SNS

Spallation Neutron Source

TTF

Target Test Facility

VFD

variable frequency drive 
This page is intentionally left blank. 


\section{DEMONSTRATION AND FEASIBILITY ANALYSES OF USING THE DUAL-PURPOSE CANISTER DRAIN PIPE TO SUPPORT THE FILLING PROCESS}

\section{INTRODUCTION}

This report documents work performed for the US Department of Energy (DOE) Nuclear Energy Spent Fuel and Waste Disposition, Spent Fuel and Waste Science and Technology. This work was performed under work breakdown structure element 1.08.01.03.05, "Direct Disposal of Dual-Purpose Canisters." In particular, this report fulfills the M4 milestone M4SF-19OR0103050116, "Initial Full-scale/Scaled-drain Pipe Filling Experiment and Data Collection" within work package SF-19OR01030501, "Direct Disposal of Dual-Purpose Canisters-ORNL."

Dual-purpose (storage and transportation) canisters (DPCs) are used to store the majority of the spent nuclear fuel (SNF) nationwide. DPCs are licensed, designed, and fabricated for storage and transportation only. However, there are many potential benefits of directly disposing DPCs in a geological repository, including billions of dollars in savings. During the feasibility determination for direct disposal of DPCs, criticality was identified as a DPC disposal concern. Several options are being examined to demonstrate the feasibility of DPC direct disposal, one of which is to fill the DPCs before disposal. The DPC filler material can prevent flooding of DPCs in a repository time frame, thus reducing the potential for a DPC criticality event.

One option under consideration is to fill the DPCs with liquid metals and/or other filler materials through the existing drain pipe. Due to the high specific gravity of metals, filling through this pipe after creating a liquid film on the pipe wall is conceivable, resulting in a two-phase, annular flow regime. If properly organized and controlled, the filling process could be smooth and continuous, without pulses, vibrations, or other hydraulic effects that may compromise the operation.

While literature describes many experimental and analytical studies of vertical annular flows in pipes, most use water or other light liquids as the filler material. It is difficult to find any studies using liquid metals, which differ from water in density and surface tension. These properties are extremely important in the development of annular film flow. Experimenting with liquid metals can lead to proving the feasibility of filing through the drain pipe. Numerical simulations of computational fluid dynamics (CFD) can be performed in parallel with the experimental tests to compliment the assessment and to allow for scaling the problem to the full-sized DPC.

Most of the metals are solid at normal room conditions. Because bringing the metals to liquid state for experimentation would be expensive, an alternative is to use mercury as a surrogate metal, as its density and surface tension are equivalent to liquid lead. Oak Ridge National Laboratory (ORNL) has already developed the infrastructure necessary to experiment with mercury; this set-up can easily be adapted for DPC drain pipe fill testing. 
Demonstration and Feasibility Analyses of using the DPC Drain Pipe to Support the Filling Process

This page is intentionally left blank. 


\section{ORNL MERCURY FACILITIES}

The Target Test Facility (TTF) shown in Figure 1 is a full-scale Spallation Neutron Source (SNS) prototypical mercury loop that was recently modified to accommodate smaller test sections and a reduced flow rate.
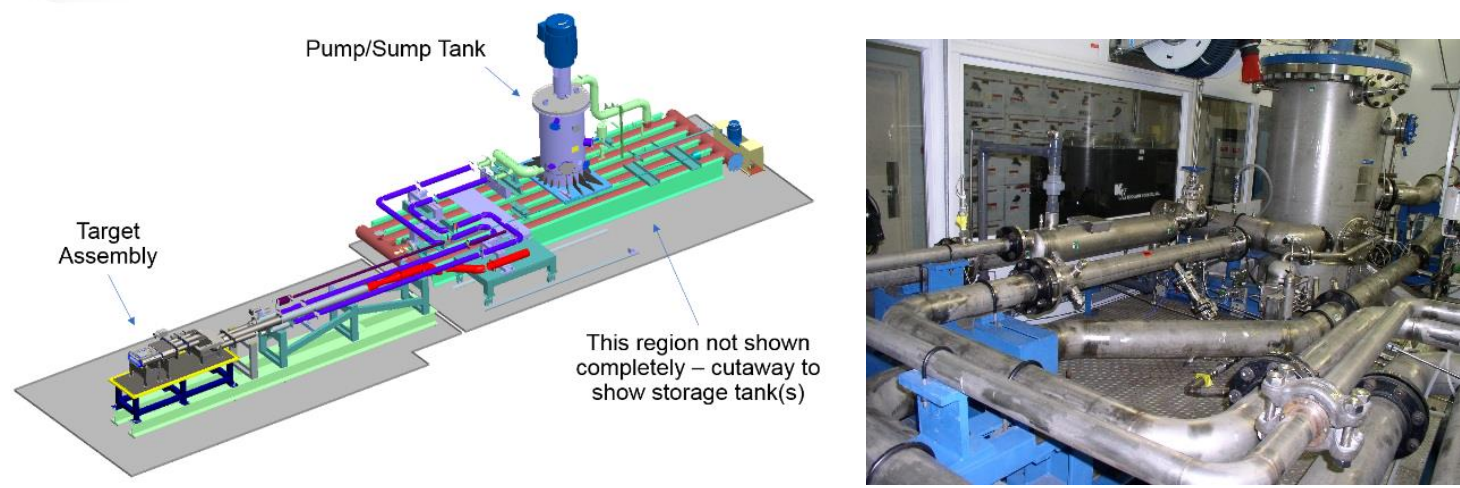

Figure 1. Target Test Facility (TTF) Mercury Loop.

The facility has an inventory of $\sim 40,000 \mathrm{lb}$ of liquid mercury and can drive a maximum of $547 \mathrm{gpm}$ using a magnetic-drive centrifugal pump and associated variable frequency drive. The typical discharge shutoff pressure is $180 \mathrm{psig}$. The facility is enclosed in an isolated room that provides independent ventilation and a filter system capable of removing mercury vapors and maintaining safety levels inside the enclosure. This facility is equipped with constant air monitors to quantify mercury vapor concentration, as well as automatic alarms inside the enclosure and its surroundings. A complete data acquisition system (DAQ) system provides control and important parameter measurements for facility operation. A team of trained personnel operates the loop and has extensive experience with mercury handling. 
Demonstration and Feasibility Analyses of using the DPC Drain Pipe to Support the Filling Process

This page is intentionally left blank. 


\section{EXPERIMENTAL SETUP}

The drain pipe experimental program was divided into two phases to provide a separate effects approach to the problem, along with system scalability. In the first phase, strain measurements were taken in a shortened representative length of the filling pipe, and flow-induced vibration was tested using a rapid modification of the existing mercury flow loop. The second phase involves design and construction of a separated mercury flow loop that can host exchangeable test sections and more localized instrumentation. Both loops will share the existing environmental enclosure, which is equipped with mercury detectors and reliable safety measures for mercury handling. This approach was necessary to avoid disrupting the existing mercury test target facility schedule and to provide adequate space.

Results obtained in Phase I of this experimental program will be used to provide guidance on important parameters of interest such as instrumentation location, instrumentation sensitivity vs. pipe wall thickness, total filling rates, mercury vapor level disruption in the test enclosure, the effect of flow pulsation on free fall jets, etc.

\subsection{Experimental Program: Phase I}

The objective of Phase I is to measure (a) liquid metal (i.e., mercury) -induced strain along vertical pipe under various flow rates, (b) induced strain at the bottom wall of the pipe due to direct impingement of the falling jet, and (c) flow-induced vibration frequency.

\subsubsection{Modification of Existing Mercury Loop}

The existing mercury loop consists of a storage tanks, a sump tank, a test section, a heat exchanger, and 3-6-inch stainless steel piping (Figure 1). The loop was modified to accommodate a standard vertical schedule 40 steel pipe that is 2 inches in diameter and 74 inches long sch 40 to provide prototypical flow rates for filling applications. The drain pipe size varies with canister design and manufacturer. Table 1 provides specifications of various canister designs and the experimental conditions used during Phase I.

Table 1. Typical canister drain-pipe sizes and experimental pipe tested in Phase I.

\begin{tabular}{c|c|c|c|l}
\hline $\begin{array}{c}\text { Canister main } \\
\text { drain pipe } \\
\text { diameter (in) }\end{array}$ & $\begin{array}{c}\text { Wall } \\
\text { thickness } \\
\text { (in) }\end{array}$ & $\begin{array}{c}\text { Experiment } \\
\text { pipe } \\
\text { diameter } \\
\text { (in) }\end{array}$ & $\begin{array}{c}\text { Experiment } \\
\text { wall thickness } \\
\text { (in) }\end{array}$ & Notes \\
\hline 0.75 & 0.05 & 2 & 0.154 & \\
\hline 1 & 0.133 & 2 & 0.154 & \\
\hline 1 & 0.25 & 2 & 0.154 & \\
\hline 1.25 & 0.05 & 2 & 0.154 & \\
\hline 2 & 0.035 & 2 & 0.154 & NAC canister with support plates \\
\hline
\end{tabular}

The location selected for this inclusion was the sump tank which has a direct discharge to the storage tanks, as shown in Figure 2. The implemented vertical pipe and associated control valves were fed using one of the main mercury lines in the system through a 1-inch port located downstream from the pump. The operation of the vertical pipe experiment requires the flow of mercury through the whole system while directing a very small volume $(<5 \%)$ of flow-in comparison with the total volumetric flow rate capacity - towards the vertical pipe test section. The lower part of the vertical test pipe was connected with a $45^{\circ}$ elbow to a pipe driving the mercury down to the storage tanks. Therefore, the addition of the vertical pipe was considered a closed loop operation. One disadvantage of this once-through configuration is the decreasing mercury level inside the sump tank with time. The decrease of the liquid level in the tank will eventually trip the low liquid level alarm to avoid pump damage. Before this trip point, the 
experimental run must be stopped to move the dumped liquid in the storage tanks back into the main system. This operation takes approximately 2 hours, as the system refilling is accomplished by creating vacuum conditions inside the main mercury loop.

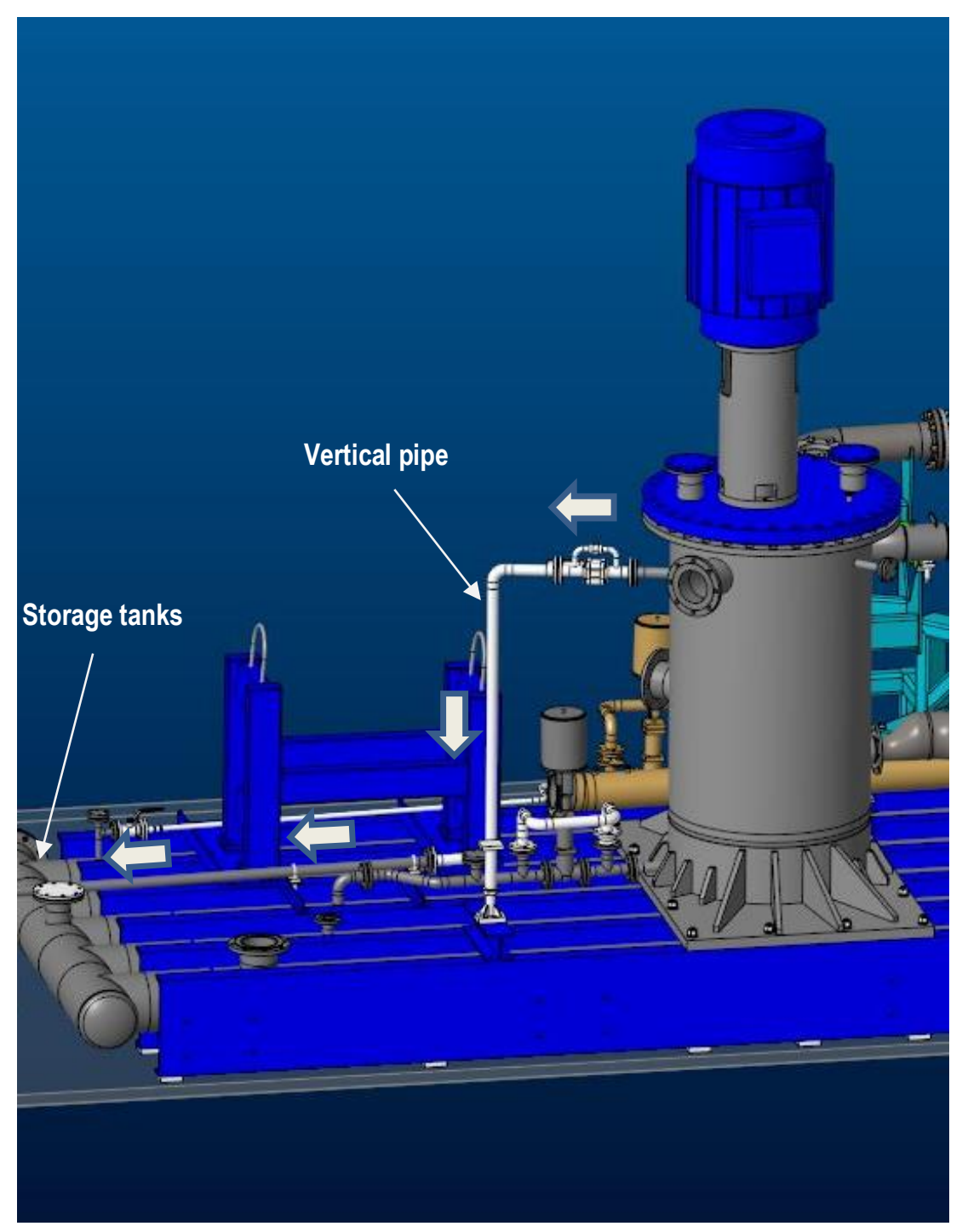

Figure 2. Vertical Pipe Location.

\subsubsection{Strain Measurements in the Vertical Pipe}

A distributed fiber sensor with a design based on the use of fiber optics with fiber Bragg gratings (FBGs) was installed to characterize the strain distribution along the vertical pipe and at the bottom external surface of the elbow. Dedicated fibers with a diameter of $0.150 \mathrm{~mm}$ were attached to the surface of the vertical pipe and at the bottom external wall of the $45^{\circ}$ elbow using bonding epoxy to characterize strain measurements, as shown in Figure 3. 


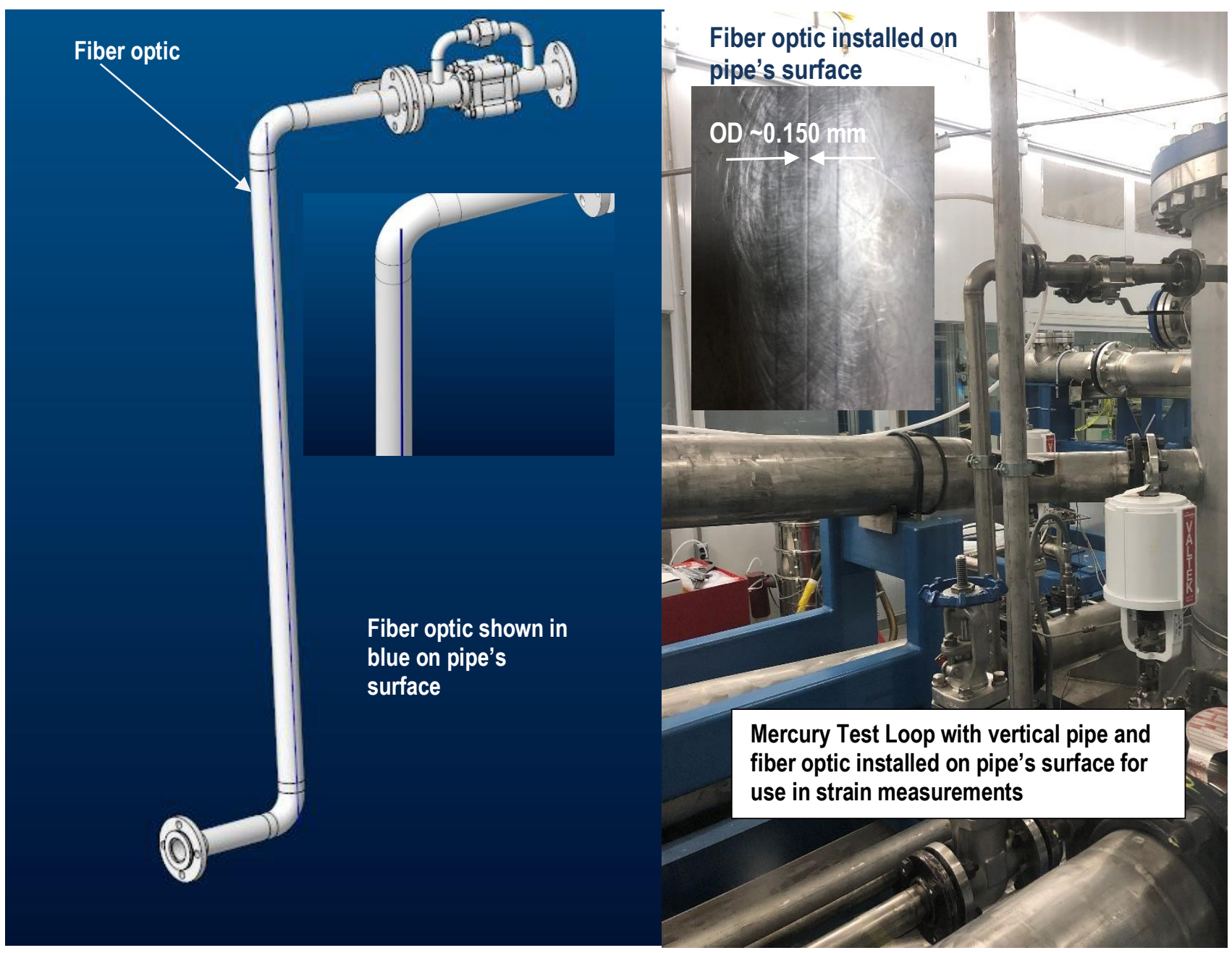

Figure 3. Vertical Pipe with Distributed Fiber Optic Sensor for Strain Measurements.

\subsection{Experimental Program: Phase II}

Phase 2 of the experimental program considers the design of an independent low volume mercury loop that will share the current test facility's environmental enclosure. The design and construction of this secondary liquid metal loop will provide a more versatile way to place exchangeable test sections and will provide more realistic flow conditions as expected during the DPC drain pipe filling operation. The design of this small volume loop was conceived in parallel with activities in Phase I, and design considerations are as follows.

\subsubsection{Phase II Experiment Loop Design}

The loop considers the accommodation of small-to-medium flow rates on the order of 0.3-30 gpm. The loop will allow for testing and study of liquid film filling processes at the initial filling phase, in combination with higher flow rates once a stable filling rate has been established. The design also allows for the use of a low-pressure storage tank with filters and gas coverage to emulate the DPC, with a drain at the bottom. An electromagnetic pump with its suction side connected to the storage tank will drive the fluid up to a height of $\sim 138$ inches to an elevated tank. A secondary peristatic pump located at the same 
elevation of the secondary tank will provide constant low flow rates for film filling tests by homogenously distributing flow to a central pipe located between the two tanks for liquid downfall testing, as shown in Figure 4.

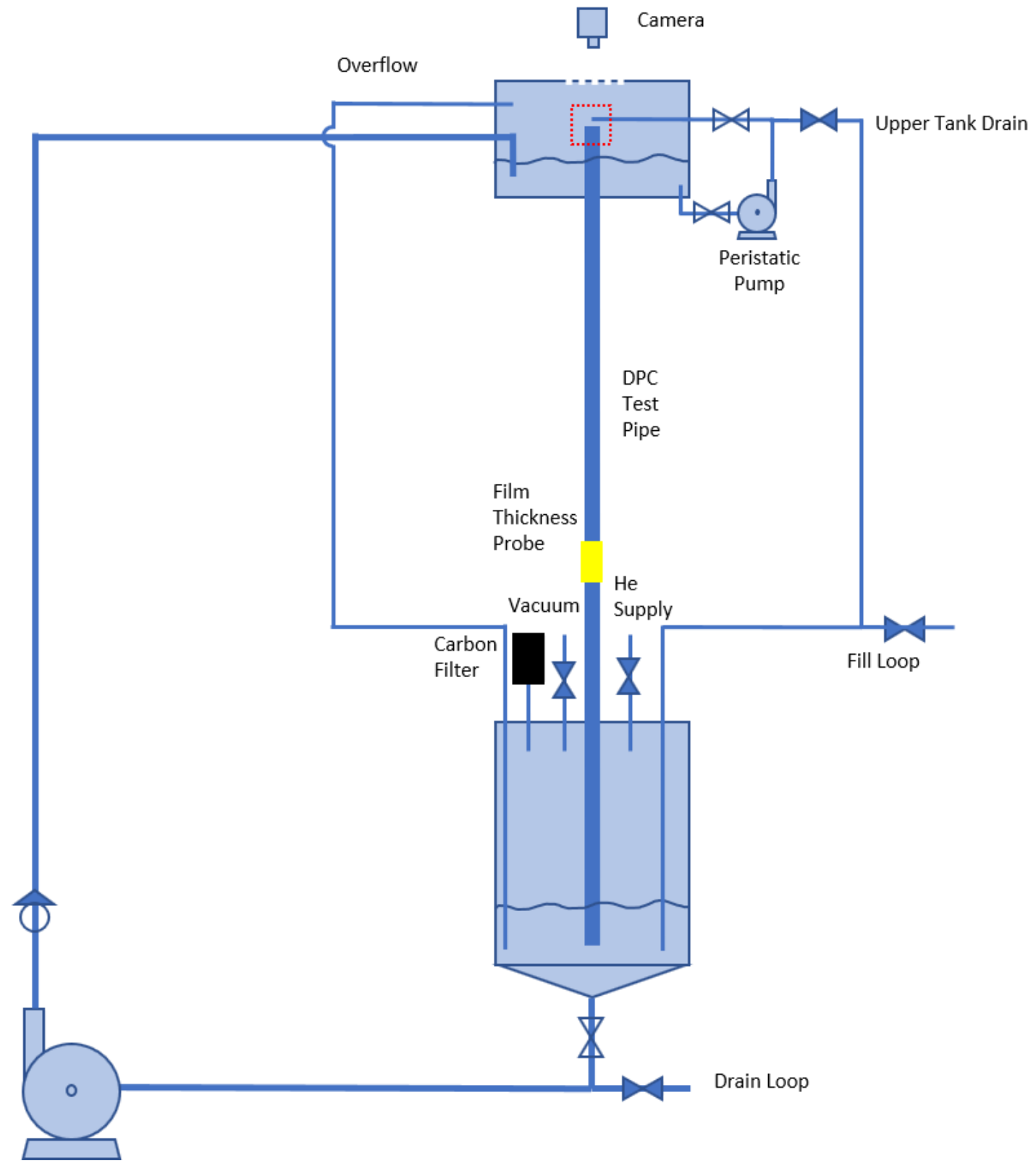

Figure 4. Low Volume Mercury Loop.

The generation of an annular type flow at the top of the testing tube was explored using three main venues for the design of the pipe inlet (a) the pebble bed, (b) the bell-mouthed spillway, and (c) the symmetric mesh filter, as shown in Figure 5. These three designs were successfully demonstrated in previous works [1] using water as a working fluid. 

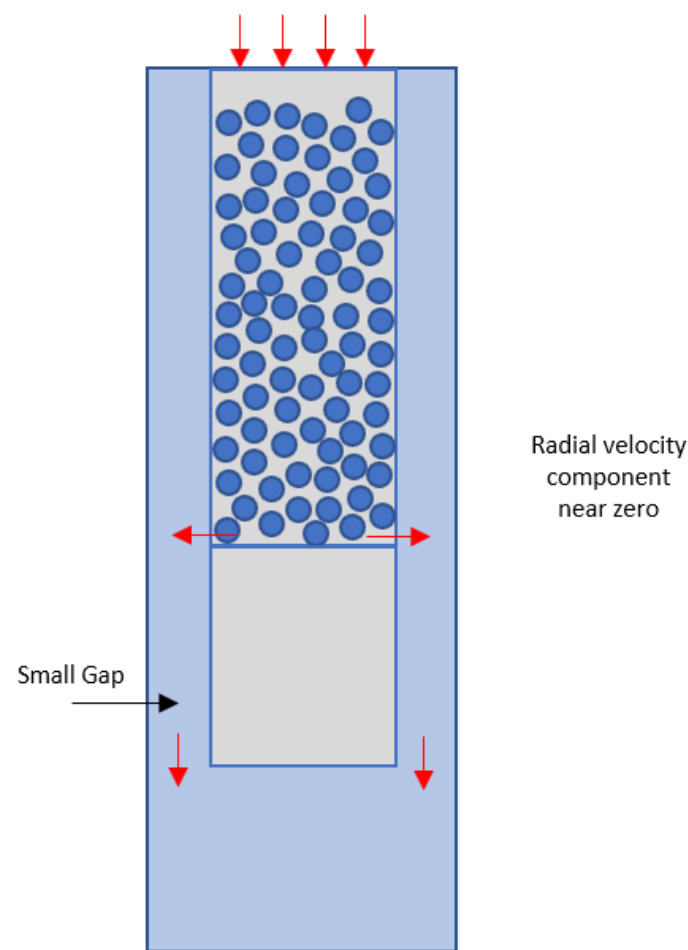

a. Pebble bed

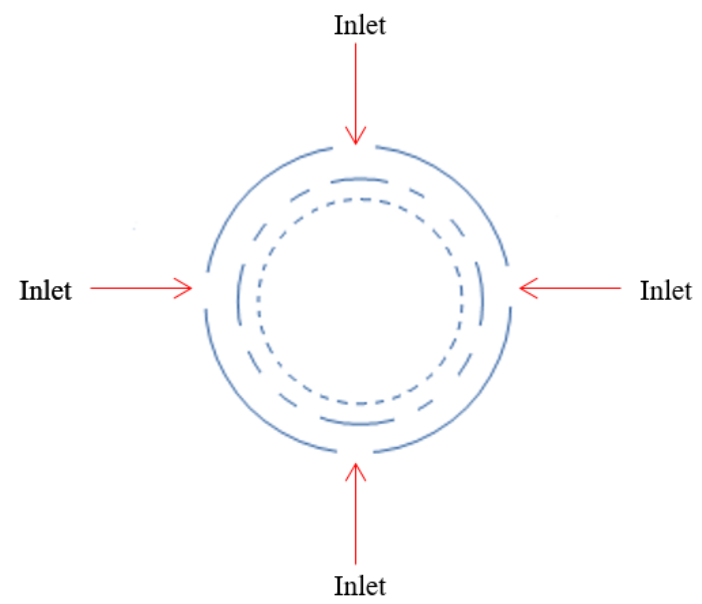

Top View

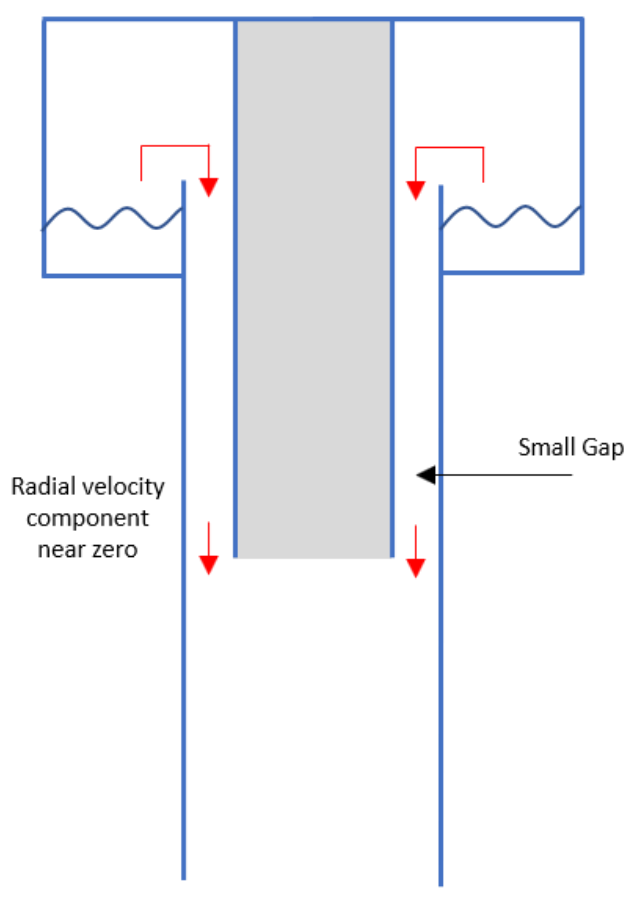

b. Bell-mouthed spillway

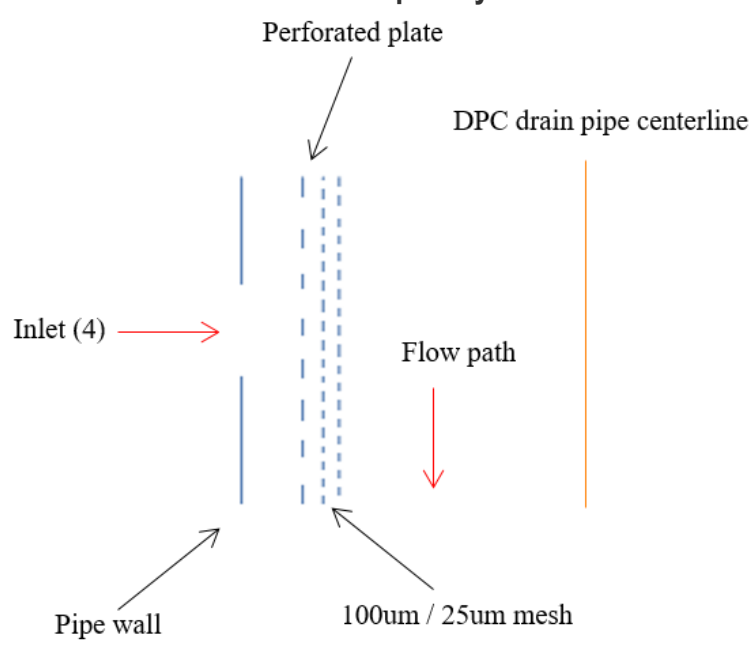

Side View

c. Symmetric mesh filter

Figure 5. Pipe Entrance for Annular Type Inlet Flow.

A derived analytical solution of the velocity profile for laminar internal annular flow provided an estimation of film thicknesses and assisted in component sizing. In prior works [6-7], experimental annular film studies were performed on pipes of similar sizes relative to the DPC drain pipe, with diameters between 12.7-25.4 mm. Figure 6 shows the relationship between film thickness, pipe diameter, and flow rate, assuming the velocity profile for laminar internal annular flow for mercury. Prior water- 
based annular film flow experiments achieved film thicknesses up to $3 \mathrm{~mm}$. As can be seen, the flow rates required for thick (up to $3 \mathrm{~mm}$ ) mercury films appear to be extremely large and are certainly not under laminar conditions. Therefore, the only analytical conclusion is that expected mercury films will be very thin. It is noted that the expected film thickness for a given turbulence level will be significantly decreased in the case of mercury. Moreover, due to its high-density, which will result in a higher Reynolds number (Re), mercury films are expected to become unstable at very low velocities when compared with water results.
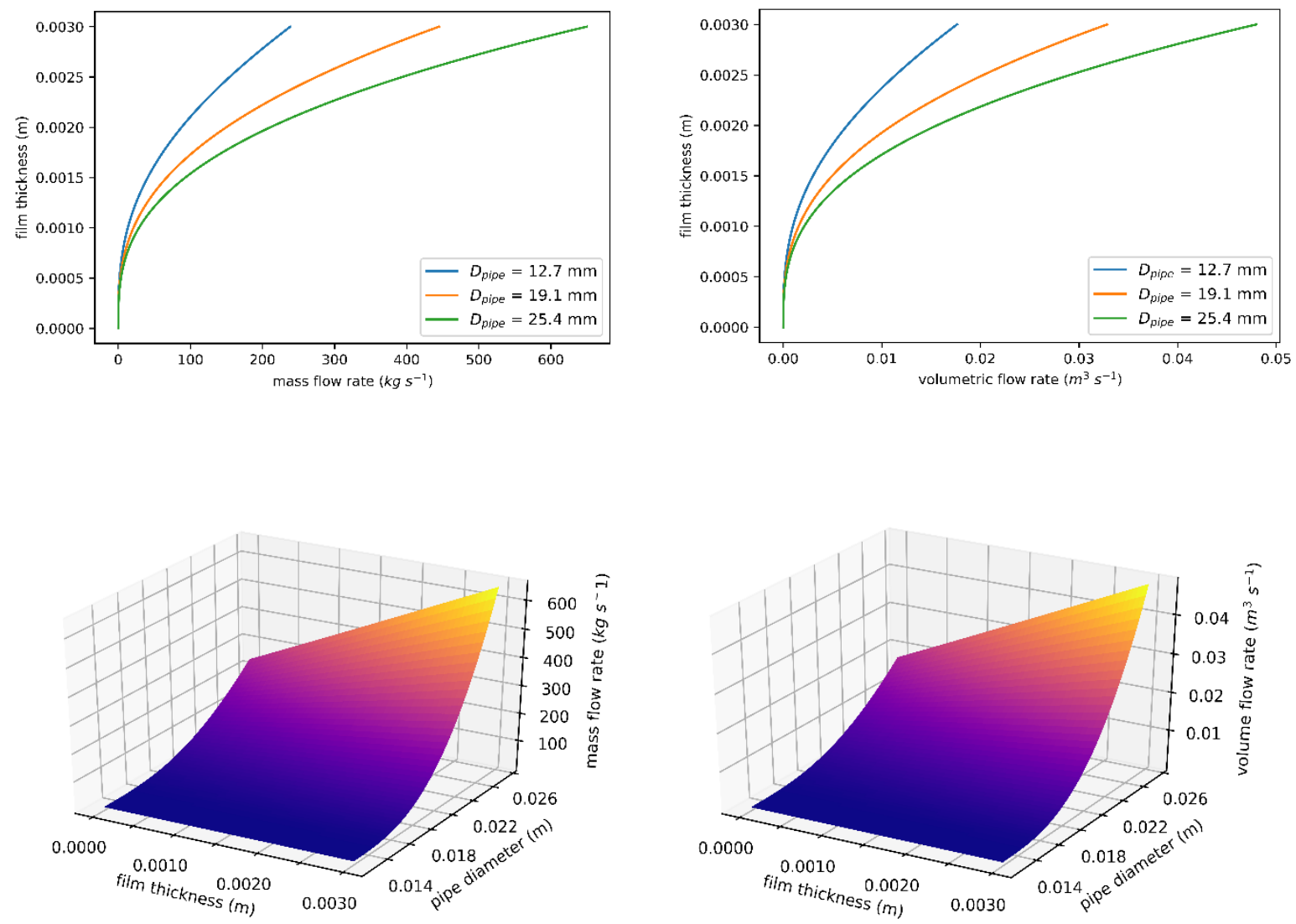

\section{Figure 6. Analytical Solutions of Expected Mercury Film Thickness for Pipe Diameters Between 12.7-25.4 mm under the Laminar Internal Annular Film Flow Assumption [6-7].}

A second approach to estimating film thickness and flow rate was to use existing water-based empirical correlations for annular film flow.

To achieve a better approximation to the expected film thickness in the test section and flow rate for component sizing, water-based empirical correlations involving viscosity, density, and Re (no explicit surface tension terms) were explored [6,8,9].

Table 2 shows the calculated film thickness in the test tube for the cases of water and mercury. It can be observed that expected film thicknesses are small and will represent a challenge for the proposed conductance probe since all of the thicknesses are in a range of less than one millimeter and will require very low flow rates to develop. It is planned to modify electrode size in conductance probe to overcome this problem. 
Table 2. Expected film thickness for various flow rates with mercury and water.

\begin{tabular}{l|c|c|c|c|c|c}
\hline MERCURY & $\begin{array}{c}\text { Re } \\
\text { number }\end{array}$ & $\begin{array}{c}\text { Velocity } \\
(\mathbf{m} / \mathbf{s})\end{array}$ & $\begin{array}{c}\text { Film } \\
\text { thickness } \\
(\mathbf{m})\end{array}$ & $\begin{array}{c}\text { Flow rate } \\
(\mathbf{m} \wedge \mathbf{3} / \mathbf{s})\end{array}$ & $\begin{array}{c}\text { Flow rate } \\
(\mathbf{m L} / \mathbf{s})\end{array}$ & $\begin{array}{c}\text { Flow rate } \\
(\mathbf{g p m})\end{array}$ \\
\hline Laminar $\rightarrow$ transition & $2.70 \mathrm{E}+02$ & $2.40 \mathrm{E}-03$ & $9.99 \mathrm{E}-05$ & $9.48 \mathrm{E}-09$ & $9.48 \mathrm{E}-03$ & $1.50 \mathrm{E}-04$ \\
\hline $\begin{array}{l}\text { Lower limit of } \\
\text { correlation }\end{array}$ & $5.00 \mathrm{E}+02$ & $4.44 \mathrm{E}-03$ & $1.39 \mathrm{E}-04$ & $2.44 \mathrm{E}-08$ & $2.44 \mathrm{E}-02$ & $3.87 \mathrm{E}-04$ \\
\hline $\begin{array}{l}\text { Midpoint of correlation } \\
\begin{array}{l}\text { Upper limit of } \\
\text { correlation }\end{array}\end{array}$ & $6.75 \mathrm{E}+03$ & $5.99 \mathrm{E}-02$ & $5.65 \mathrm{E}-04$ & $1.29 \mathrm{E}-06$ & $1.29 \mathrm{E}+00$ & $2.05 \mathrm{E}-02$ \\
\hline WATER & $1.30 \mathrm{E}+04$ & $1.15 \mathrm{E}-01$ & $8.04 \mathrm{E}-04$ & $3.47 \mathrm{E}-06$ & $3.47 \mathrm{E}+00$ & $5.49 \mathrm{E}-02$ \\
\hline Laminar $\rightarrow$ transition & $2.70 \mathrm{E}+02$ & $1.81 \mathrm{E}-02$ & $3.84 \mathrm{E}-04$ & $2.69 \mathrm{E}-07$ & $2.69 \mathrm{E}-01$ & $4.26 \mathrm{E}-03$ \\
\hline $\begin{array}{l}\text { Lower limit of } \\
\text { correlation }\end{array}$ & $5.00 \mathrm{E}+02$ & $3.35 \mathrm{E}-02$ & $5.35 \mathrm{E}-04$ & $6.85 \mathrm{E}-07$ & $6.85 \mathrm{E}-01$ & $1.09 \mathrm{E}-02$ \\
\hline $\begin{array}{l}\text { Midpoint of correlation } \\
\text { Upper limit of } \\
\text { correlation }\end{array}$ & $6.75 \mathrm{E}+03$ & $4.52 \mathrm{E}-01$ & $2.17 \mathrm{E}-03$ & $3.24 \mathrm{E}-05$ & $3.24 \mathrm{E}+01$ & $5.14 \mathrm{E}-01$ \\
\hline
\end{tabular}

\subsubsection{Loop Components}

The components to be used in the fabrication of the testing loop were selected during this reporting time period. The following list presents the main considerations during component selection (Figure 4).

a. Working fluid = elemental mercury

i. Chemical compatibility of wetted surfaces

1. Initial specification for lift pump met typical mercury wetted surface requirements of stainless steel, viton, and polytetrafluoroethylene (PTFE). However, it was determined that the impeller was built using silver solder in the welding process, which is not acceptable with mercury due to the inevitable amalgamation of mercury/silver and resulting impeller damage.

2. Acceptable methods have been defined in the TTF Equipment Specification for Mercury Processing

a. Document \# JS-XMT-017109-A001

ii. Density at $25 \mathrm{C}=13,534 \mathrm{~kg} / \mathrm{m}^{\wedge} 3$

iii. Absolute viscosity at $25 \mathrm{C}=0.001526 \mathrm{~Pa} \mathrm{~s}$

iv. Surface tension at $25 \mathrm{C}=485.5 \mathrm{mN} / \mathrm{m}$

b. Lift pump

i. Equipment specifications:

ii. Pump part number: UC1518LAECSSVS8121429

iii. Model: UC1518L

iv. FTI's low flow ULTRAChem, AA ANSI dimensional mag-drive centrifugal pump

v. $1.5 \times 1$-inch flanged suction and discharge

vi. PTFE-lined volute and wetted plastic components 
vii. Exterior components protected with solvent-based epoxy primer and Dupont Imron ${ }^{\text {̀े }}$ catalyzed polyurethane enamel topcoat

viii. Close-coupled design

ix. "A" magnet set

x. Alpha sintered silicon carbide bushing

xi. Alpha sintered silicon carbide shaft

xii. FKM O-ring

xiii. 8.125-inch diameter impeller

xiv. NEMA 143/145TC motor adapter

xv. $* 2 \mathrm{hp}, 1,725 \mathrm{rpm}, 60 \mathrm{~Hz}, 3$-phase, $230-460 \mathrm{v}$, NEMA $145 \mathrm{TC}$ frame, TEFC motor (included)

xvi. Minimum required flow of $1 \mathrm{gpm}$

c. Lift pump variable frequency drive (VFD)

i. Equipment specifications:

ii. VFD model number: WEG CFW500

d. Peristatic metering pump

i. Cole-Parmer Masterflex L/S peristaltic pump (in marketplace)

1. Flow rate $0.001-3,400 \mathrm{~mL} /$ minute with $\mathrm{L} / \mathrm{S}$ tubing (Flow rate depends on drive rpm and tubing size.)

2. Control and monitoring via ethernet connect

3. Brushless, maintenance-free motor offers $\pm 0.1 \%$ speed control accuracy with a 6,000-to-1 turndown ratio

e. Lower plenum

i. Tank 1

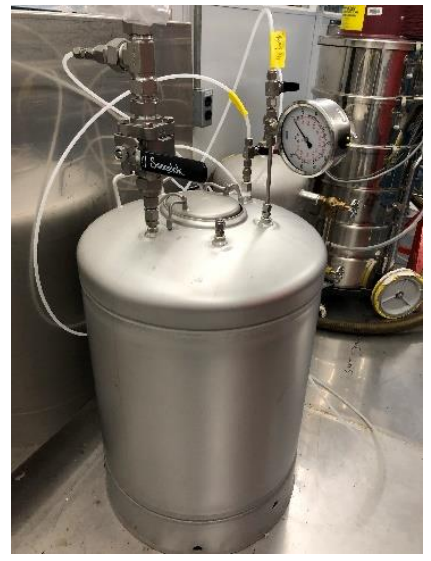

ii. Stainless steel easy-drain tanks

1. 30-gallon, 18 inches in diameter, 45 inches in length 


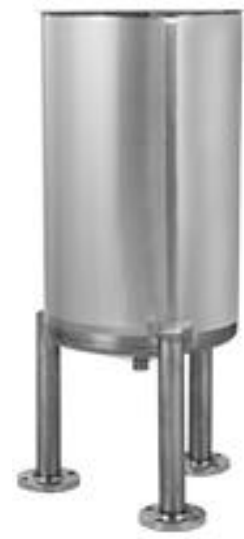

iii. Small commercial tank (not sourced yet)

f. Upper plenum

i. Tank at TTF

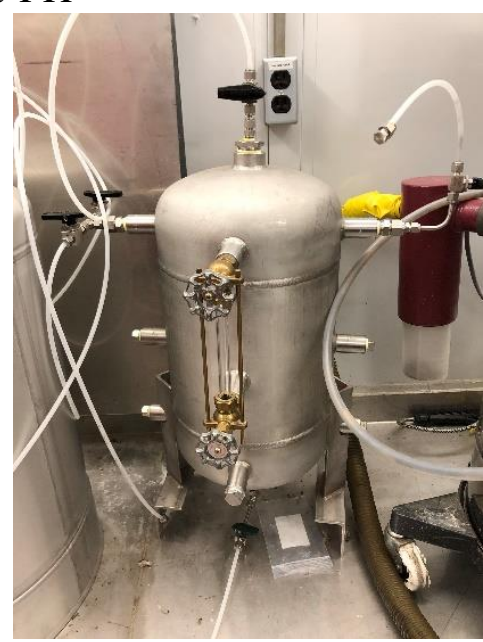

ii. Commercial tank (not sourced yet)

g. Piping

i. SS316L, SCH40, seamless

h. Valves

i. Swagelok stainless steel 3-piece 60 series valves

1. Reinforced PTFE seats ( $\times 750$ seats available)

2. 1-inch pipe socket weld

i. Flanges

i. $\mathrm{SS} 316 \mathrm{~L}$

ii. Neck weld

iii. $150 \mathrm{lb}$

iv. Gasket

1. Spiral wound SS304 winging rings with PTFE

j. Instrument sensors

i. Film thickness

1. Capacitance

2. Conductance

3. Develop fiber probe 
Demonstration and Feasibility Analyses of using the DPC Drain Pipe to Support the Filling

Process

14

ii. Pressure

1. Static pressure transducers

2. Static differential pressure transducers

3. Dynamic pressure transducers

iii. Temperature

1. Resistance temperature detector

2. Thermocouples 


\section{RESULTS}

The data acquired during this reporting time period are related to Phase I of the experimental program. The raw data have been acquired under various mercury flow rate conditions of interest. However, data reduction and analysis have not been performed at this writing. A plan to perform the indicated data analysis and data reduction is being developed and will be submitted in a future report. The preliminary data shown in Figure 7 present the strain measurements performed at the external wall of the bottom elbow in the vertical pipe test under a flow rate of $2 \mathrm{~L} / \mathrm{m}$. The plot shows a deflection amplitude in the negative $\mathrm{Y}$ axis direction, indicating a higher impingement of mercury liquid in those areas. The $\mathrm{X}$ axis represents the spatial location of an FBG along the fiber, and the Y axis represents the strain amplitude measured at a specific time (snapshot). Therefore, spatially resolved strain measurements were performed at different axial locations along the tested pipe. The measured directions of interest are predetermined during fiber installation.

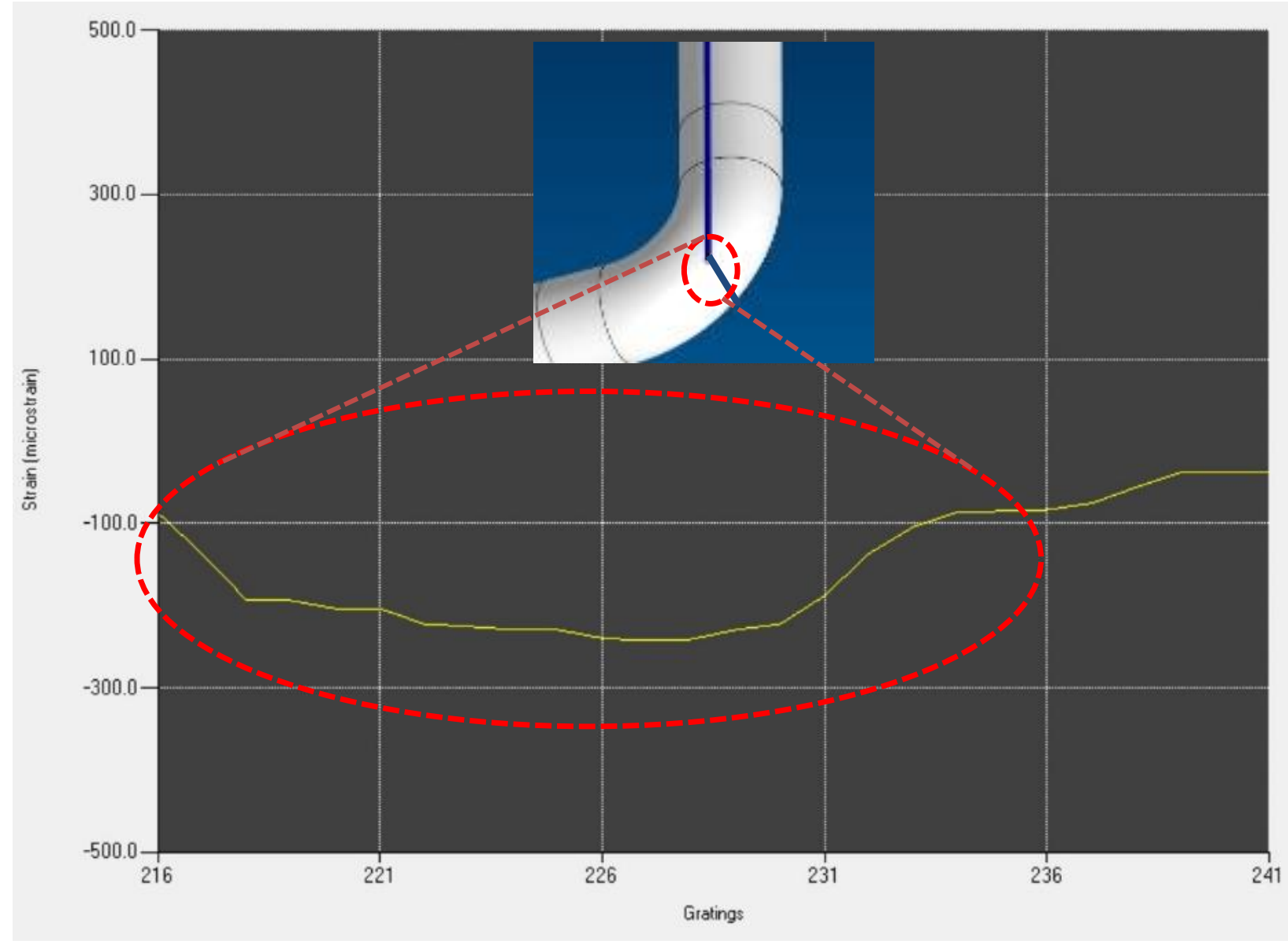

Figure 7. Pipe Strain at Bottom Wall of the Elbow. The Mercury Column Provides a Measurable Strain on the Outside Wall.

Figure 8 presents a 3D waterfall plot of the same data set presented Figure 7, where the $\mathrm{Y}$ axis represents the sensor location along the fiber, the $\mathrm{X}$ axis represents the elapsed time, and the color scale represents the strain amplitude measured. This type of representation allows for visualization of the strain amplitude change patterns as a function of time. In this case, the elapsed time between strips of color represent the 
impingement frequency of liquid metal at the bottom wall of the elbow. The same type of analysis can be used to obtain pipe vibration frequency by analyzing the FBGs located along the vertical pipe axis instead of those located at the bottom of the elbow. This is one of the advantages of the selected strain measurement system, where thousands of sensors along the fiber can be interrogated simultaneously with high spatial and high temporal resolution.

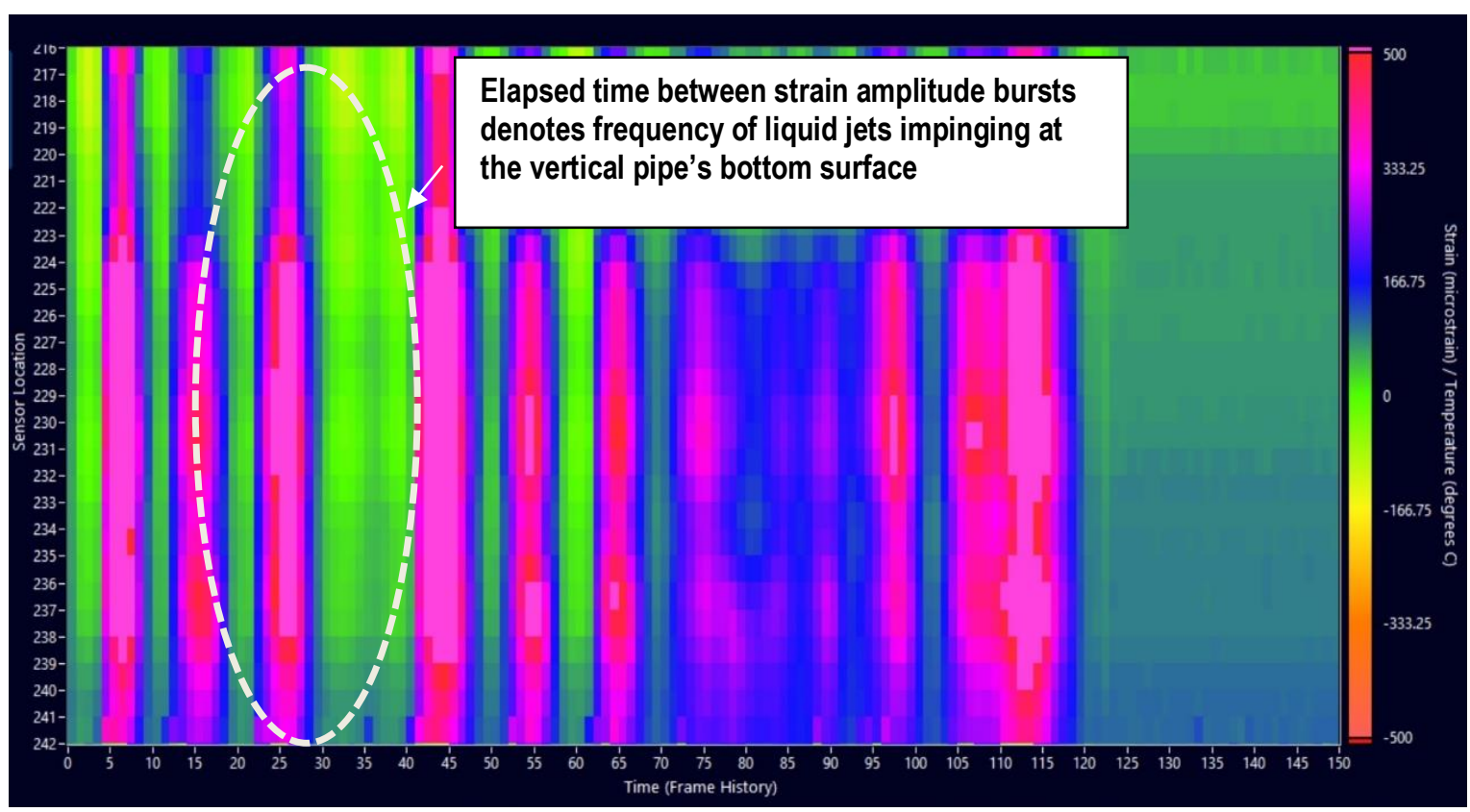

Figure 8. Frequency of Liquid Mercury Impingement at Bottom Surface of Vertical Pipe. 


\section{CONCLUSIONS}

The drain pipe experimental program was divided into two phases to provide a separate effects approach to the problem and to allow for development of system scalability. The first phase included taking strain measurements in a shortened -half of typical DPC- representative length of the filling pipe, as well as measurements of flow-induced vibration using a rapid modification of the existing mercury flow loop. The second phase consists of the design and construction of a separated mercury flow loop capable of hosting exchangeable test sections and more localized instrumentation.

Data acquisition of Phase I was performed during this reporting time period, and subsequent data reduction and data analysis will be performed in the future.

Design of the secondary low-volume liquid metal loop was also performed, along with analysis of the expected film thickness range and loop performance evaluation. Material selection and procurement were initiated. 
Demonstration and Feasibility Analyses of using the DPC Drain Pipe to Support the Filling Process

This page is intentionally left blank. 


\section{REFERENCES}

1. Karapantsios, T. D., S. T. Paras, and A. J. Karabelas, "Statistical Characteristics of Free-Falling Films at High Reynolds Numbers, Int. J. Multiphase Flow, 15(1), 1-21, (1989).

2. Belkin, H. H., A. A. MacLeod, C. C. Monrad, and R. R. Rothfus, "Turbulent Liquid Flow Down Vertical Walls," AIChE Journal, 5(2), 245-248 (1959).

3. Ritchey, S. N., M. Solom, O. Draznin, I. Choutapalli, and K. Vierow, "Flooding Experiments with Steam and Water in a Large-Diameter Vertical Tube," Nucl. Technol., 175(3), 529-537 (2011).

4. Padmanaban, A., "Film Thickness Measurements in Falling Annular Films," Doctoral Dissertation (2006).

5. Ogrosky, H. R., "Modeling Liquid Film Flow Inside a Vertical Tube," Doctoral Dissertation, The University of North Carolina at Chapel Hill (2013).

6. Karapantsios, T. D., and A. J. Karabelas, "Longitudinal Characteristics of Wavy Falling Films," Int. J. of Multiphase Flow, 21(1), 119-127 (1995).

7. Sinkunas, S., J. Gylys, and A. Kiela, "Analysis of Laminar Liquid Film Flowing Down a Vertical Surface." 4th Int. Conf. CFD in the Oil and Gas, Metall. and Process Industries (pp. 1-5), (2005).

8. Paras, S.V. and A. J. Karabelas, "Properties of the Liquid Layer in Horizontal Annular Flow," Int. J. Multiphase Flow, 17(4), 439-454 (1991).

9. Fore, L. B. and A. E. Dukler, "Droplet Deposition and Momentum Transfer in Annular Flow," AIChE J. 41(9), 2040-2046, (1995). 